Original Article

\title{
Effect of maitland mobilization in cervical and thoracic spine and therapeutic exercise on functional impairment in individuals with chronic neck pain
}

\author{
Keun-Su Lee, $\mathrm{PT}^{1)}$, JoON-HeE Lee, $\mathrm{PhD}^{2)^{*}}$ \\ 1) Department of Physical Therapy, Graduate School of Health Sciences, Cheongju University, \\ Republic of Korea \\ 2) Department of Physical Therapy, Cheongju University: 298 Daesung-ro, Cheongwon-gu, Cheongju, \\ Chungcheongbuk-do, Republic of Korea
}

\begin{abstract}
Purpose] This study evaluated joint mobilization and therapeutic exercise applied to the cervical spine and upper thoracic spine for functional impairment caused by chronic neck pain. [Subjects and Methods] Eighteen study subjects were randomly assigned to two groups of nine people each. Therapeutic exercise only was applied to the cervical and upper thoracic spine for Group I, while both therapeutic exercise and joint mobilization were applied to Group II. The visual analog scale, neck disability index, active cervical range of motion, static balance capacity, and muscle tone were assessed with a pre-test. The intervention was carried out for 60 minutes a day, three times a week, for two weeks for each group, followed by a post-test using the same protocol as the pre-test. [Results] The visual analog scale, neck disability index, and active cervical range of motion improved significantly in both groups. Group II improved significantly more on right lateral flexion and rightward rotation. Muscle tone improved significantly in the upper trapezius in both groups. [Conclusion] The joint mobilization and therapeutic exercise for functional impairments caused by chronic neck pain had a significant effect on several types of functional impairment.

Key words: Chronic neck pain, Mobilization, Therapeutic exercise
\end{abstract}

(This article was submitted Jul. 5, 2016, and was accepted Dec. 14, 2016)

\section{INTRODUCTION}

Neck pain is a common musculoskeletal disorder in modern society that can produce severe pain. $67 \%$ of the population suffers from it at least once in a lifetime and the prevalence is about $23 \% 1{ }^{1)}$. The pain exacerbates and fades periodically, and many patients do not fully recover from the symptoms ${ }^{2}$. Neck pain occurs in the upper thoracic spine area including the shoulder, and it is mechanical pain caused by bad postures and habits in most cases ${ }^{3)}$. According to Sharon, the upper thoracic spine is involved in the physiologic motion of the neck ${ }^{4)}$. The decreased movement of the upper cervical spine can cause excessive movement of the lower cervical spine, increase fatigue in the sternocleidomastoid, anterior scalenus, and upper trapezius, cause changes of neck postures and breathing patterns, and a decrease in the range of motion ${ }^{5}$. Patients with chronic neck pain experience functional impairments including weakening of deep bending neck muscles due to the activation of neck surface muscles ${ }^{6}$, increased deformity of the forward head posture ${ }^{7)}$, proprioception impairment ${ }^{8)}$, and poor balance ${ }^{9}$. In addition, decreased movement of the cervical spine restricts the range of motion of the spine and decreases breathing function ${ }^{10,11)}$. Slightly bent positions like the forward head posture may cause mechanical neck pain, cause a greater load by affecting the mobilization order of the muscles operating when the arm is raised, and restrict the range of motion ${ }^{12)}$. These

*Corresponding author. Joon Hee Lee (E-mail: pieta2000@hanmail.net)

(C2017 The Society of Physical Therapy Science. Published by IPEC Inc.

This is an open-access article distributed under the terms of the Creative Commons Attribution Non-Commercial No Derivatives (by-nc-nd) License $<$ http://creativecommons.org/licenses/by-nc-nd/4.0/>. 
changes reduce the ability to maintain balance and increase the risk of falls and injury of the musculoskeletal system ${ }^{9}$.

Physiotherapists are using methods such as electrotherapy, therapeutic exercise, and manual therapy to intervene in the neck pain ${ }^{13)}$. In a Cochrane review study of neck pain, stretching exercises for the neck and upper limbs, strengthening exercises, static and dynamic stabilization exercises were recommended as highly effective ${ }^{14}$. Maitland mobilization grade 3 and 4 treatment for the cervical spine and upper spine significantly decreases neck disability index (NDI), the pain index ${ }^{15)}$, and increases the range of motion ${ }^{16}$. In addition, an the intervention combining therapeutic exercise and manual therapy was significantly more effective compared to manual therapy alone ${ }^{17)}$. Recent evidence-based studies report that treatment combining therapeutic exercise and manual therapy is more effective ${ }^{18)}$, but research of combined interventions is sparse. The purpose of this study was to apply joint mobilization and therapeutic exercise to the cervical spine and upper spine, investigate the effects on functional impairments caused by the neck pain, and examine differences between groups by comparing the intervention group with the group to which only therapeutic exercises were applied.

\section{SUBJECTS AND METHODS}

This study was implemented with non-specific neck pain patients with no medical findings who had visited the Cheongju St. Mary's Hospital in Republic of Korea for more than three month. The eighteen participants of this study had not participated in any similar research. All participants received verbal and written information about the study and signed a consent form. This study was approved by Cheongju University's Research and Ethics Committee. The patients who had undergone or would have surgery in the spine, and those who had neurological damage, a cervical spine fracture, osteoporosis, arthritis, a malignant neoplasm, a vascular disease, or a psychiatric problem were excluded. The subjects were randomly assigned to one of two groups of nine people each. Group I was the therapeutic exercise group, and Group II was the group to which joint mobilization was applied in combination with therapeutic exercise (Table 1). The pretest included the visual analog scale (VAS), neck disability index (NDI), active cervical range of motion (ACROM), static balance ability, muscle tone of the upper trapezius, and respiratory function. After the pretest, Group I performed therapeutic exercise and Group II performed both therapeutic exercise and joint mobilization for 60 minutes a day, three times a week for two weeks under the guidance of a physical therapist. The participants did not receive any other interventions associated with the neck pain while this research was being conducted. The post-test was carried out with the same protocol as the pretest after two weeks.

Therapeutic exercises involved enhancing mobility, stability and muscular strength of the neck, improving proprioception, and performing reeducation of movement, and the intensity of exercises was adjusted according to the physical abilities of the individuals. For the joint mobilization, Maitland Grade 3 and 4 were used depending on the subjects' condition. After the painful sites were located by examination, the active movement test was conducted to find where joint mobilization would be applied, and the amount and quality of motion were examined. Afterwards, passive physiological intervertebral movement (PPIVM) testing and passive intervertebral accessory movement (PAIVM) test were conducted to find which joints had restricted or excessive movement, and determine where joint mobilization would be applied. The VAS was employed to measure the intensity of pain $^{19)}$, the NDI was used to measure neck pain disability ${ }^{20)}$, and CROM instrument to assess the cervical range of motion ${ }^{21)}$. In order to check static balance, I Balance S (CyberMedic Co., Iksan, Korea) was utilized ${ }^{9}$. Myoton PRO (Myoton AS, Estonia) measured the muscle tone of the upper trapezius ${ }^{22}$, and a spirometer (Pony FX Spirometer; COSMED, Rome, Italy) measured the respiratory function ${ }^{23)}$

Data were analyzed using the SPSS 22.0 statistical program (SPSS, Inc., an IBM Company, Chicago, IL, USA). For the normality test, the Shapiro Wilk test was conducted, confirming that the data are normally distributed. Assuming homogeneity between groups, the independent samples t-test was performed, and the paired sample t-test was conducted for the within-group comparison of the measurements before and after the interventions. In addition, the independent samples t-test was conducted to compare the differences between groups. Null hypotheses of no difference were rejected if p-values were less than 0.05 .

Table 1. General characteristics of the subjects $(n=18)$

\begin{tabular}{lcc}
\hline & Group I & Group II \\
\hline Gender (female) & 9 & 9 \\
Age (years) & $58.0 \pm 1.6$ & $59.0 \pm 2.4$ \\
Height $(\mathrm{cm})$ & $158.0 \pm 3.9$ & $157.0 \pm 4.7$ \\
Weight $(\mathrm{kg})$ & $58.0 \pm 4.6$ & $59.0 \pm 6.6$ \\
\hline Values are expressed as Mean \pm SD. \\
*Significant difference between Pre-Post test (p<0.05) \\
†Significant difference between groups (p<0.05) \\
Group I (therapeautic exercise), Group II (mobilization \& \\
therapeautic exercise)
\end{tabular}




\section{RESULTS}

VAS and NDI led to significant changes in both groups, and Group II improved significantly more than Group I (Tables 2, 3). The ACROM increased significantly in both groups, and Group II improved significantly more on the right lateral flexion and rightward rotation than Group I (Table 4). Both groups improved significantly in static balance, with no difference between groups (Tables 5, 6). Muscle tone in the left and right upper trapezius muscle improved significantly in both groups, and there was no difference between groups (Table 7).

Table 2. Visual Analog Scale of the subjects

\begin{tabular}{llc}
\hline & Group I & Group II \\
\hline Pre & $4.8 \pm 0.4$ & $4.9 \pm 0.3$ \\
Post & $2.7 \pm 0.5^{*}$ & $1.4 \pm 05^{*} \dagger$ \\
\hline *Significant & difference between Pre-Post test \\
$(\mathrm{p}<0.05)$ & & \\
+ Significant & difference & between groups \\
$(\mathrm{p}<0.05)$ & &
\end{tabular}

Table 4. Active Cervical Range of Motion of the subjects $\left(^{\circ}\right)$

\begin{tabular}{llll}
\hline & & \multicolumn{1}{c}{ Group I } & Group II \\
\hline \multirow{2}{*}{ Flexion } & Pre & $49.2 \pm 8.7$ & $48.9 \pm 4.7$ \\
& Post & $54.2 \pm 4.5$ & $56.1 \pm 6.8^{*}$ \\
Extension & Pre & $54.9 \pm 4.3$ & $56.4 \pm 4.9$ \\
& Post & $64.3 \pm 3.2^{*}$ & $67.6 \pm 3.9^{*}$ \\
Rt. & Pre & $38.4 \pm 2.2$ & $35.8 \pm 3.0$ \\
Side Flex & Post & $42.4 \pm 2.1^{*}$ & $42.1 \pm 2.1^{*} \dagger$ \\
Lt. & Pre & $38.6 \pm 2.2$ & $37.3 \pm 2.1$ \\
Side Flex & Post & $43.2 \pm 1.7^{*}$ & $42.7 \pm 2.0^{*}$ \\
Rt. & Pre & $61.4 \pm 6.4$ & $58.0 \pm 5.8$ \\
Rotation & Post & $65.2 \pm 5.6^{*}$ & $66.6 \pm 5.6^{*} \dagger$ \\
Lt. & Pre & $60.8 \pm 3.2$ & $59.7 \pm 5.1$ \\
Rotation & Post & $67.6 \pm 3.6^{*}$ & $67.7 \pm 4.2^{*}$ \\
\hline
\end{tabular}

*Significant difference between Pre-Post test $(\mathrm{p}<0.05)$ $\uparrow$ Significant difference between groups $(\mathrm{p}<0.05)$

Table 6. Center of gravity total sway distances of each group under different conditions $(\%)$

\begin{tabular}{llll}
\hline & & Group I & Group II \\
\hline Firm-eyes & Pre & $294.6 \pm 64.1$ & $304.6 \pm 97.9$ \\
open & Post & $270.4 \pm 66.4$ & $281.9 \pm 64.8$ \\
Firm-eyes & Pre & $299.7 \pm 52.4$ & $302.6 \pm 64.3$ \\
closed & Post & $272.2 \pm 21.8$ & $290.2 \pm 60.1$ \\
Foam-eyes & Pre & $473.1 \pm 137.8$ & $477.9 \pm 116.7$ \\
open & Post & $389.3 \pm 100.9$ & $400.6 \pm 109.2$ \\
Foam-eyes & Pre & $618.2 \pm 82.7$ & $687.3 \pm 182.8$ \\
closed & Post & $529.1 \pm 88.2^{*}$ & $548.4 \pm 172.5^{*}$ \\
\hline
\end{tabular}

*Significant difference between Pre-Post test $(\mathrm{p}<0.05)$

$\dagger$ Significant difference between groups $(\mathrm{p}<0.05)$
Table 3. Neck Disability Index of the subjects

\begin{tabular}{lcc}
\hline & Group I & \multicolumn{1}{c}{ Group II } \\
\hline Pre & $15.1 \pm 2.3$ & $17.2 \pm 3.1$ \\
Post & $8.9 \pm 1.5^{*}$ & $8.6 \pm 1.9^{*} \dagger$ \\
\hline *Significant & difference between Pre-Post test \\
$(\mathrm{p}<0.05)$ & & \\
+ Significant & difference & between groups \\
$(\mathrm{p}<0.05)$ & &
\end{tabular}

Table 5. Center of gravity sway velocities of each group under different conditions $(\%)$

\begin{tabular}{llcc}
\hline & & Group I & Group II \\
\hline Firm-eyes & Pre & $0.04 \pm 0.0$ & $0.05 \pm 0.0$ \\
open & Post & $0.03 \pm 0.0$ & $0.04 \pm 0.0$ \\
Firm-eyes & Pre & $0.15 \pm 0.0$ & $0.15 \pm 0.0$ \\
closed & Post & $0.14 \pm 0.0$ & $0.14 \pm 0.0$ \\
Foam-eyes & Pre & $0.25 \pm 0.1$ & $0.25 \pm 0.1$ \\
open & Post & $0.22 \pm 0.1$ & $0.22 \pm 0.1$ \\
Foam-eyes & Pre & $0.35 \pm 0.1$ & $0.37 \pm 0.1$ \\
closed & Post & $0.30 \pm 0.1^{*}$ & $0.32 \pm 0.1^{*}$ \\
\hline
\end{tabular}

*Significant difference between Pre-Post test $(\mathrm{p}<0.05)$

$\uparrow$ Significant difference between groups $(p<0.05)$

Table 7. Muscle tone of the subjects

\begin{tabular}{llll}
\hline & & Group I & Group II \\
\hline Rt. Upper & Pre & $15.3 \pm 1.8$ & $15.6 \pm 1.4$ \\
trapezius & Post & $14.4 \pm 1.5^{*}$ & $14.2 \pm 1.3^{*}$ \\
Lt. Upper & Pre & $16.0 \pm 1.5$ & $16.0 \pm 1.2$ \\
trapezius & Post & $13.7 \pm 1.3^{*}$ & $14.2 \pm 1.4^{*}$ \\
\hline
\end{tabular}

*Significant difference between Pre-Post test $(\mathrm{p}<0.05)$

$\dagger$ Significant difference between groups $(\mathrm{p}<0.05)$ 


\section{DISCUSSION}

Chronic neck pain patients suffer diverse functional impairments, including a deterioration of balance ability, respiratory function, range of joint motion, and proprioception ${ }^{11)}$. Research related to neck pain suggests that there are more efficient interventions based on evidence through systematic reviews, and the interventions combining manual therapy and therapeutic exercise are described as more effective in recent literature ${ }^{18}$. In this study, therapeutic exercises were conducted that are reported to be effective for patients with mechanical neck pain, namely, stretching exercise for the neck and upper limbs, static and dynamic stability exercise, strengthening exercise, and exercise reeducation ${ }^{14)}$. In addition, as manual therapy, mobilization to reduce pain and improve the movements of the soft tissue exhibiting contracture and restricted motions of joints (Maitland Grade III and IV) ${ }^{13,24)}$ were applied to Group II. The effect of the two kinds of interventions, and group differences based on those interventions were examined. In this research, a significant reduction in the VAS and NDI was observed in both groups, and the comparison between the groups showed that the intervention was more effective in Group II. This result is different from studies that found no difference between groups based on a short-term intervention ${ }^{17)}$. These differences may result from our smaller number of subjects and differences of individual characteristics. For the ACROM, both groups improved significantly overall, and Group II improved more on right lateral flexion and rightward rotation. These results are consistent with studies that reported that mobilization applied to both the neck and spine at the same time improved cranial vertical angle and cranial rotation angle ${ }^{25)}$ and research that showed that endurance exercise of the neck, stabilization exercise, and strength training improved the joint range of motion ${ }^{26)}$.

In this study, static balance was measured under a variety of conditions, including hard or soft bearing surfaces and open or closed eyes. A significant decrease in the sway velocity of the center of gravity and in the sway distance occurred only under eyes closed, and there was no difference between groups. Although it was reported that patients with neck pain and forward head posture may exhibit reduced balance ability ${ }^{9}$, it was possible to measure the static balance ability most accurately when the soft bearing surface was used and eyes were closed to block the visual feedback. Muscle tone of the upper trapezius decreased significantly in both groups, and there was no difference between the groups. This may indicate that the tension and fatigue of the upper trapezius were reduced due to pain reduction, enhancement of mobility of the neck joints, and change in the mobilization sequence of movements caused by afferent information activation of proprioception ${ }^{5)}$. Deterioration of mobility of the spine and thoracic cage was reported in patients of chronic neck pain, and respiratory function was also affected ${ }^{27}$. However, in this research, no significant change in the respiratory function was observed. This may be because the patients were not given direct training for functional improvement of breathing muscles, although the range of motion of the cervical and upper thoracic spine was improved through the study interventions. The limitations of this study are as follows. The number of subjects was small, and since the period of intervention was not long, it was difficult to produce a mechanical change of muscles. Therefore, future research is required to investigate the effect of joint mobilization and therapeutic exercise on the functional impairments caused by chronic neck pain using diverse subjects and intervention periods, and research on the persistence of the effect also needs to be conducted.

In conclusion, joint mobilization and therapeutic exercise for functional impairments caused by chronic neck pain significantly improved several types of functional impairment. In addition, in the group to which both joint mobilization and therapeutic exercise were applied, significantly more improvement in the pain index, neck disability levels, and ACROM was seen than in the group that received only therapeutic exercise.

\section{REFERENCES}

1) Hoy DG, Protani M, De R, et al.: The epidemiology of neck pain. Best Pract Res Clin Rheumatol, 2010, 24: 783-792. [Medline] [CrossRef]

2) Côté P, Cassidy JD, Carroll LJ, et al.: The annual incidence and course of neck pain in the general population: a population-based cohort study. Pain, 2004, 112: 267-273. [Medline] [CrossRef]

3) Cagnie B, Cools A, De Loose V, et al.: Differences in isometric neck muscle strength between healthy controls and women with chronic neck pain: the use of a reliable measurement. Arch Phys Med Rehabil, 2007, 88: 1441-1445. [Medline] [CrossRef]

4) Tsang SM, Szeto GP, Lee RY: Normal kinematics of the neck: the interplay between the cervical and thoracic spines. Man Ther, 2013, 18: 431-437. [Medline] [CrossRef]

5) Kapreli E, Vourazanis E, Strimpakos N: Neck pain causes respiratory dysfunction. Med Hypotheses, 2008, 70: 1009-1013. [Medline] [CrossRef]

6) Falla DL, Jull GA, Hodges PW: Patients with neck pain demonstrate reduced electromyographic activity of the deep cervical flexor muscles during performance of the craniocervical flexion test. Spine, 2004, 29: 2108-2114. [Medline] [CrossRef]

7) Yip CH, Chiu TT, Poon AT: The relationship between head posture and severity and disability of patients with neck pain. Man Ther, 2008, 13: 148-154. [Medline] [CrossRef]

8) Sjölander P, Michaelson P, Jaric S, et al.: Sensorimotor disturbances in chronic neck pain — range of motion, peak velocity, smoothness of movement, and repositioning acuity. Man Ther, 2008, 13: 122-131. [Medline] [CrossRef]

9) Lee JH: Effects of forward head posture on static and dynamic balance control. J Phys Ther Sci, 2016, 28: 274-277. [Medline] [CrossRef]

10) Dimitriadis Z, Kapreli E, Strimpakos N, et al.: Respiratory weakness in patients with chronic neck pain. Man Ther, 2013, 18: 248-253. [Medline] [CrossRef]

11) Kapreli E, Vourazanis E, Billis E, et al.: Respiratory dysfunction in chronic neck pain patients. A pilot study. Cephalalgia, 2009, 29: 701-710. [Medline] 
[CrossRef]

12) Malmström EM, Olsson J, Baldetorp J, et al.: A slouched body posture decreases arm mobility and changes muscle recruitment in the neck and shoulder region. Eur J Appl Physiol, 2015, 115: 2491-2503. [Medline] [CrossRef]

13) Masaracchio M, Cleland JA, Hellman M, et al.: Short-term combined effects of thoracic spine thrust manipulation and cervical spine nonthrust manipulation in individuals with mechanical neck pain: a randomized clinical trial. J Orthop Sports Phys Ther, 2013, 43: 118-127. [Medline] [CrossRef]

14) Kay TM, Gross A, Goldsmith CH, et al.: Exercises for mechanical neck disorders. Cochrane Database Syst Rev, 2012, (8): CD004250. [Medline]

15) Cleland JA, Glynn P, Whitman JM, et al.: Short-term effects of thrust versus nonthrust mobilization/manipulation directed at the thoracic spine in patients with neck pain: a randomized clinical trial. Phys Ther, 2007, 87: 431-440. [Medline] [CrossRef]

16) Suvarnnato T, Puntumetakul R, Kaber D, et al.: The effects of thoracic manipulation versus mobilization for chronic neck pain: a randomized controlled trial pilot study. J Phys Ther Sci, 2013, 25: 865-871. [Medline] [CrossRef]

17) Bronfort G, Evans R, Nelson B, et al.: A randomized clinical trial of exercise and spinal manipulation for patients with chronic neck pain. Spine, 2001, 26: 788-797, discussion 798-799. [Medline] [CrossRef]

18) Miller J, Gross A, D’Sylva J, et al.: Manual therapy and exercise for neck pain: a systematic review. Man Ther, 2010, 15: 334-354. [Medline] [CrossRef]

19) Bijur PE, Silver W, Gallagher EJ: Reliability of the visual analog scale for measurement of acute pain. Acad Emerg Med, 2001, 8: 1153-1157. [Medline] [CrossRef]

20) Song KJ, Choi BW, Kim SJ, et al.: Cross-cultural adaptation and validation of the Korean version of the neck disability index. J Korean Orthop Assoc, 2009, 44: 350-359. [CrossRef]

21) Lind B, Sihlbom H, Nordwall A, et al.: Normal range of motion of the cervical spine. Arch Phys Med Rehabil, 1989, 70: 692-695. [Medline]

22) Aird L, Samuel D, Stokes M: Quadriceps muscle tone, elasticity and stiffness in older males: reliability and symmetry using the MyotonPRO. Arch Gerontol Geriatr, 2012, 55: e31-e39. [Medline] [CrossRef]

23) Han D, Yoon N, Jeong Y, et al.: Effects of cervical self-stretching on slow vital capacity. J Phys Ther Sci, 2015, 27: 2361-2363. [Medline] [CrossRef]

24) Young JL, Walker D, Snyder S, et al.: Thoracic manipulation versus mobilization in patients with mechanical neck pain: a systematic review. J Manual Manip Ther, 2014, 22: 141-153. [Medline] [CrossRef]

25) Lee J, Lee Y, Kim H, et al.: The effects of cervical mobilization combined with thoracic mobilization on forward head posture of neck pain patients. J Phys Ther Sci, 2013, 25: 7-9. [CrossRef]

26) Ylinen J, Takala EP, Nykänen M, et al.: Active neck muscle training in the treatment of chronic neck pain in women: a randomized controlled trial. JAMA, 2003, 289: 2509-2516. [Medline] [CrossRef]

27) Wirth B, Amstalden M, Perk M, et al.: Respiratory dysfunction in patients with chronic neck pain —influence of thoracic spine and chest mobility. Man Ther, 2014, 19: 440-444. [Medline] [CrossRef] 